\begin{tabular}{|l|l|}
\hline Postprint Version & Final draft post-refereeing \\
\hline Journal website & $\underline{\text { http://www.springerlink.com/content/1053-0487 }}$ \\
\hline Pubmed link & $\underline{\text { http://www.ncbi.nlm.nih.gov/pubmed/20623164 }}$ \\
\hline DOI & $\underline{10.1007 / s 10926-010-9255-3}$ \\
\hline
\end{tabular}

\title{
The effect of recalled previous work environment on return to work after a rehabilitation program including vocational aspects for trauma patients
}

\author{
Pierluigi Ballabeni, Cyrille Burrus, François Luthi, Charles Gobelet, Olivier Dériaz \\ P. Ballabeni (correspondence), C. Burrus, F. Luthi, C. Gobelet, O Dériaz \\ Clinique romande de réadaptation suvaCare, Case postale 352, Avenue Grand-Champsec $90, \mathrm{CH}-$ \\ 1951 Sion, Switzerland \\ e-mail: pierluigi.ballabeni@crr-suva.ch \\ P. Ballabeni \\ Institute of Social and Preventive Medicine (IUMSP), Centre Hospitalier Universitaire Vaudois and \\ University of Lausanne, Lausanne, Switzerland
}

\section{Suggested running head}

Effects of recalled previous work environment on return to work

\begin{abstract}
Introduction The aim of the present study was to assess the association between remembered previous work place environment and return to work (RTW) after hospitalisation in a rehabilitation hospital.

Methods A cohort of 291 orthopedic trauma patients discharged from hospital between 15 December 2004 and 31 December 2005 was included in a study addressing quality of life, and workrelated questions. Remembered previous work environment was measured by Karasek's 31-item Job Content Questionnaire (JCQ), given to the patients during hospitalisation. Post-hospitalisation work status was assessed 3 months, 1 and 2 years after discharge, using a questionnaire sent to the expatients. Logistic regression models were used to test the role of four JCQ variables on RTW at each time point while controlling for relevant confounders.

Results Subjects perceiving a higher physical demand were less likely to return to work 1 year after hospital discharge. Social support at work was positively associated with RTW at all time points. A high job strain appeared to be positively associated with RTW 1 year after rehabilitation, with limitations due to large confidence intervals.

Conclusions Perceptions of previous work environment may influence the probability of RTW. In a rehabilitation setting, efforts should be made to assess those perceptions and, if needed, interventions to modify them should be applied.

(211 words)
\end{abstract}

Keywords Sick leave, Vocational rehabilitation, Trauma, Workplace, Return to work, Perception. 


\section{Introduction}

Sickness benefits, disability benefits and employment injury benefits form a significant part of the increase in total welfare spending that has occurred in the industrialised countries over the past few decades [1]. While rehabilitation programs aim to favour the social and professional reintegration of injured or diseased people, they also contribute to decrease the costs to society due to sick leave, early retirement, reduced productivity, payment of state benefits or reduced tax payments [1]. Understanding the factors influencing return to work after rehabilitation can help establishing strategies to reduce sick leave that go beyond rehabilitation alone.

After traumatic injury, sick leave can last for long, and it is now admitted that return to work (RTW) does not only depend on the severity of injury. Factors affecting RTW in patients with musculoskeletal disorders may be classified in four main categories [2] that also apply to any other disorder [37]: personal characteristics, either demographic or psychosocial; medical factors; socio-economic factors; factors related to the employer or the workplace, including psychological factors related to work as job satisfaction or job stress.

The notion of psychosocial factors at the workplace was developed in the late twentieth century, following the concept of stress which appeared in 1936 [8]. The most used model assessing psychosocial environment on the workplace is Karasek's demand-control model $[9,10]$. According to this model, the worst influence on health results from a combination of high psychological demand and a low job control, a situation defined as high job strain. In this paradigm job stress is assessed using the Job Content Questionnaire (JCQ), which can address 4 stressor dimensions that are job control, psychological demand, social support and physical demand. Job strain has been shown to be associated with determinants of health, in particular cardiovascular risk factors [11, 12], and stroke $[13,14]$. Within worker cohort studies, a high psychological demand has been found to be negatively associated with back pain [15] and positively associated with compensation claims due to strain, sprain, contusion or pain of the spine [16]; low job control was associated to low management support and musculoskeletal pain or low back pain [17]. The JCQ has also been used in RTW analysis. Sick leave has been found to be positively associated with high job strain $[18,19]$, especially if combined with a low social support [19], and with a co-occurrence of low psychological demand and high job control [20]. Social support perceived at the workplace was found to be associated with RTW in a study on low back pain workers on sick-leave[21].

Individual subjective perceptions are found to be of great importance in the RTW process. Patient beliefs and perceptions can have an effect on disease chronicity and thus on RTW [22]. For example, pain and fear avoidance were negatively associated with RTW[23]. Work related psychosocial perceptions depend on employee emotional response to workplace demands and stressors, and are based on individual's cognitive, emotional, and behavioural responses[24].

Patients on vocational rehabilitation after traumatic injuries have relatively long sick leave periods. Therefore, if the previous workplace conditions have an influence on the RTW, this should be mediated by how the patients recall their workplace at the end of their rehabilitation program is likely to be relevant. We therefore used the JCQ to test whether the previous workplace environment as recalled shortly before dismissal from a rehabilitation clinic could influence the probability of RTW up to two years after dismissal.

\section{Methods}

\section{Study setting and participants}

The present investigation is a subproject of the OUTCOME study, a prospective cohort study of patients enrolled in 2 Swiss rehabilitation hospitals after othopedic trauma. OUTCOME investigates several quality of life and socio-economic variables by means of self-report questionnaires distributed to the patients at the beginning and the end of hospitalisation, and sent to them 3 months, 1 year and 2 years after discharge.

Patients with severe traumatic brain injury (Glasgow coma sজalie), spinal cord injury, insufficient judgment capacity, or under legal custody were considered as ineligible for the OUTCOME 
study. All other patients coming for rehabilitation after a traumatic injury were eligible. Patients signed an informed consent form before entering the study. The protocol was approved by the ethical committee of the local medical association.

The present RTW investigation took place in one of the two hospitals, the Clinique romande de réadaptation (CRR) at Sion, where we used the validated French version of the JCQ [25]. The JCQ was given one or two days before hospital discharge to all of those 304 OUTCOME participants who were discharged between 15 December 2004 and 31 December 2005. We excluded from the present analysis 8 patients with too many missing data for the JCQ to be scored and 5 others who, being older than 60 years, were considered too old to have a reasonable chance to return to work. Thus, 291 participants were entered in the analysis.

Most of our inpatients are blue collar workers and come to our facility after work or traffic accidents to take part to a rehabilitation program including treatment and interdisciplinary evaluation of patients after traumatic injuries. Patients are sent to our rehabilitation hospital when they present persistent pain and functional limitations after an accident (median: 9 months after the accident). The aim of the therapeutic program is to take care of patients with a multidisciplinary approach (somatic and psychological) in order to improve patient quality of life, functional status and chance of returning to work. At the end of the hospitalization (median duration 29 days) a program is defined in order to plan a return to the former workplace which may sometimes be adapted to the disability. If necessary, other medical measures are decided, as for instance new surgery.

\section{Measures}

Remembered work environment was assessed at the end of hospitalization by means of the 31-items JCQ. Psychometric properties of the French version of the JCQ had previously shown satisfactory results in a cohort of workers. Cronbach's alpha ranged from 0.77 for the psychological demand subscale to 0.85 for the physical demand subscale[25].

Job control was assessed with 9 items (assessment of learning abilities at work, creativity, repetitiveness, decisional power, variety of tasks, development of professional competencies), psychological demand with 9 items (intensity and speed needed at work, timetables, influence of contradictory orders, of other colleagues' work), social support 8 items (influence of colleagues and superior toward worker) and perceived physical demand with 5 items (very heavy load carrying at work, fast and continuous tasks at work, or uncommon working position). Each item's response ranged on a 4-level scale from 1 (totally disagree) to 4 (totally agree). Following Karasek's scoring[25], job control score ranges from 24 to 96, psychological demand from 9 to 36, social support from 8 to 32 and perceived physical demand from 5 to 20 . A high score means high control, demand or support.

According to the demand-control model[ 9,10$]$, we created a binary job-strain variable by combining job control and psychological demand. Subjects scoring below the sex-specific median for job control and above the sex-specific median for psychological demand were classified in a high strain group and compared to the rest, which we called low strain group

As potential confounding factors we considered age, gender, native language (French vs. other), educational level (>9 school years vs. $<=9$ ), possession of a work contract at the moment of hospitalisation (yes vs. no), pain intensity, severity of injury, and subjective belief about health improvement (improvement vs. no improvement). Pain intensity was assessed with a 100 millimetre visual analogue scale, with a score ranging from 0 to 100 . Severity of injury was assessed following criteria of the Abbreviated Injury Scale (AIS) of 1998[26], a severe injury resulting in a high score, ranging from 1 to 6 . Pain intensity and belief about improvement were assessed just before hospital discharge. All other confounders were assessed within 3 days from hospitalisation. RTW was evaluated by a question in the OUTCOME questionnaires mailed 3 months, 1 and 2 years after discharge from the rehabilitation hospital, study participants being asked if they were working in any occupation at that time.

\section{Statistical methods}

We used logistic regressions to evaluate the association between the different domains of the JCQ and return to work. Return to work (yes vs no) 3 months, 1 and 2 years after hospitalization was the 
dependent binary variable. The predictors tested were job control, psychological demand, social support, perceived physical demand and job strain. Separate analyses were run for each time point.

First, we calculated separate regression models for each predictor adjusted for the confounders. Then we ran models in which the predictors were adjusted for each other in addition to the confounders (the fully adjusted models).

In multivariable logistic regression, it is usually considered that at least 10 events per covariate are needed to avoid bias of the regression coefficients and under or overestimation of the sample variance[27]. In this context the number of events is the less frequent outcome category[28]. In the present study, we had nine covariates (one predictor plus eight confounders) for the confounderadjusted models and either 12 (individual dimensions) or 10 (job strain) covariates for the fully adjusted models. The relevant number of events varied between 61 and 83 , depending on the model. We therefore used a propensity score approach[29] to combine all confounders into a single variable for each model. Generally speaking, a propensity score is the probability for a subject to be in a predictor category, conditional to the confounding variables. In the present study, propensity scores for job strain were calculated by fitting logistic regressions with job strain as the dependent variable and the eight confounders as the covariates. For each subject, the propensity score was the predicted probability of being high strain given the set of confounders. The four individual JCQ dimensions being continuous variables, their propensity scores were the fitted values of the linear regressions of each JCQ dimensions onto the confounders[30]. A different propensity score was calculated for each predictor and time point.

The propensity score variables were then introduced instead of the individual confounders, together with the relative predictors, into the logistic regressions with RTW as outcome. Thus, for each time point, we built (1) five confounder-adjusted models, containing each one predictor plus the relative propensity score; (2) five fully adjusted models containing each one predictor with its propensity score plus remaining predictors (see the captions of figures 1 and 2 for more details).

Since the JCQ scales have different ranges between their minimum and maximum possible values, a difference of one unit does not have the same meaning in different scales. The four JCQ scales were therefore z-score transformed using the sample means and standard deviations. A zscore indicates the deviation from the mean expressed in number of standard deviations. The $z-$ scores of job control, psychological demand, social support and perceived physical demand as well as all propensity scores were entered in the models as continuous variables, thus assuming linear relationship between them and the probability of RTW. This assumption was considered acceptable after comparing models where the predictors and the propensity scores were entered untransformed with models containing the best fractional polynomial transformations of predictors and propensity scores (only small changes in the model deviance were found[31]). The results are presented as odds-ratios (OR) with their 95\% confidence intervals (Cl). For the continuous predictors an OR refers to each increment of one standard deviation (SD). Inference was made on the basis of $95 \%$ confidence intervals, avoiding a dichotomisation in significant vs. non-significant results. All calculations were performed with the statistical package Stata 9.2[32].

Typical of a self-report investigation, several patients did not return the study questionnaires making this study prone to non-response bias. We partially controlled for non-response bias by adjusting for native language and educational level among the other confounders. These two variables were found to be associated with the probability of responding to the OUTCOME questionnaires in our clinic [33].

\section{Results}

The mean age of the 291 analysed participants was 42 years (SD 11 years). Sixty eight (23\%) of them were women. Descriptive statistics for all predictors and confounders are shown on table 1.

\section{Return to work at 3 months}

Two hundred thirty-five participants answered the survey 3 months after discharge from the hospital. Eighty-seven of them (37\%) were back to work (table 2). Those back to work had lower mean psychological and physical demand scores and a higher mean social support score. The differences in 
means between groups look small but, to be appreciated, the possible range of each variable should be considered (table 2, footnote). The working group had a slightly lower proportion of high job strain subjects than the non-working group (table 2).

After adjusting for the confounders only, the logistic regression's results are compatible with the existence of an effect of remembered physical demand and psychological demand and possibly social support (figure 1A). The chances of working at 3 months decreased with increasing physical demand (OR=0.73; 95\% Cl: 0.54-0.97) and with increasing psychological demand (OR=0.74; Cl: 0.541.01). They also increased with increasing social support ( $\mathrm{OR}=1.22 ; \mathrm{Cl}: 0.91-1.64)$. For the latter two variables, the results are also compatible with a lack of effect but an effect seems more likely than not (see confidence intervals). Not much evidence for an effect of job control (figure 1A) or job strain was found (figure 2A).

A fully adjusted model provided some more confidence in a positive effect of perceived social support on the chances of returning to work (figure 1B. OR=1.38; Cl: 0.98-1.94), whereas the results of psychological demand (OR=0.81; $\mathrm{Cl}: 0.56-1.18)$ and physical demand $(\mathrm{OR}=0.84 ; \mathrm{Cl}$ : 0.59-1.19) became inconclusive (figure 1B). The data were not incompatible with a higher RTW probability for high strain patients $(\mathrm{OR}=1.55)$ but the uncertainty about the estimator makes this result little conclusive (figure 2B. Cl: 0.72-3.34).

\section{Return to work at 1 year}

One hundred ninety-two participants responded to the questionnaire one year after discharge, 87 $(45 \%)$ of whom had returned to work (table 2). The fact that exactly the same number of participants were working at 3 months and at 1 year does not mean that they were exactly the same individuals. Actually, 60 of the participants who were working at 1 year were already working at 3 months and among the subjects who were at work at 3 months, 11 were not working at 1 year and 16 did not return the 1-year questionnaire.

Mean job control and mean social support were slightly higher for the back-to-work compared to the not-working group whereas the opposite was found for mean psychological and physical demand (table 2). Again, to better appreciate the mean differences, the variables' possible ranges should be considered (table 2, footnote). High strain was more frequent among working subjects than among non-working ones (table 2).

The results of the confounder-adjusted regression models are compatible with the existence of a negative effect of remembered physical demand on return to work (figure $1 \mathrm{C}$; $\mathrm{OR}=0.70$; $\mathrm{Cl}$ : 0.51 0.97). The data were not completely incompatible with the existence of a negative effect of psychological demand and a positive effect of social support but the degree of uncertainty is too high for the results to be conclusive (figure 1C). Job control was not associated with RTW (figure 1C). High job strain subjects were more likely to be back to work than low strain subjects; the effect was important (OR=2.48), however its estimation imprecise (figure 2A. Cl: 1.08-5.71).

After full adjustment, the negative effect of remembered physical demand remained $(\mathrm{OR}=0.69)$ but with a slightly less precise estimation (figure 1D. $\mathrm{Cl}$ : 0.47-1.02). The data were compatible with a positive association between social support and RTW but relevant uncertainty remained about this result (figure 1D. OR=1.33; Cl: 0.93-1.91). Psychological demand completely lost its association with RTW and job control remained as before without important effect (figure 1D). High strain subjects were again more likely to be at work than low strain subjects $(\mathrm{OR}=3.79)$ although the estimation was imprecise (figure 2B. Cl: 1.54-9.31).

\section{Return to work at 2 years}

Two years after discharge, 89 (56\%) out of 159 questionnaire responders had returned to work (table 2). Fifty-seven of those working at 2 years were also working at 1 year. Among those who were working at 1 year, 16 had no work at 2 years and 14 did not return the questionnaire. Again, job control's and social support's mean values were slightly higher for the back-to-work participants compared to the not-working ones, while the reverse was found for psychological and physical demand (table 2). High strain was slightly more common in the not-working group than in the back-to-work group (table2). 
The confounder-adjusted analyses were not incompatible with the existence of a positive association between social support and return to work, however with a non-negligible degree of uncertainty (figure 1E. OR=1.30; $\mathrm{Cl}: 0.90-1.89$ ). The same can be said of physical demand (figure $1 \mathrm{E}$. $\mathrm{OR}=1.78$; Cl: 0.56-1.10). Not enough evidence for an effect of job control or psychological demand was found (figure 1E). A possible positive association between job strain and RTW (OR=1.35) was accompanied by too much uncertainty for the result to be conclusive (figure $2 \mathrm{~A}$. Cl: $0.55-3.31$ ).

After full adjustment, the positive association between social support and return to work became more important (figure 1F. OR=1.43; $\mathrm{Cl}$ : 0.93-2.22), being uncertain but more likely than not. The results for the other three JCQ dimensions are again inconclusive (figure 1F). The data were compatible with a higher RTW probability for high strain patients $(\mathrm{OR}=1.78)$, however with a degree of uncertainty that made this result little conclusive (figure 2B. Cl: 0.72-3.34).

\section{Discussion}

Our results confirm the importance of patient perceptions as predictor of RTW after sick-leave, in this case hospitalisation for rehabilitation including vocational aspects after orthopedic trauma. Work environment was not assessed when subjects were still at work but at the end of rehabilitation, meaning that work environment perception was influenced by recall. This is not a weakness of our study since the perception at the time point of hospital discharge is likely to be relevant to subsequent RTW. Moreover, we show that the effect on RTW of a remembered previous workplace environment can persist long after a rehabilitation program is terminated, up to two years after rehabilitation in our study. Analogous results were recently published for long term sick-leave subjects where it was found, using a different instrument for work perception assessment, that pain-related fear-avoidance beliefs for work were an important risk factor for not returning to work three months and one year after vocational rehabilitation [6]. Other researchers found that fears and beliefs about the previous work where the best predictors for low back pain chronicity [34]. These works and ours provide an argument for vocational rehabilitation to tackle perception of the workplace environment and better focus interventions, as for example using a cognitive behavioural approach.

Conditional on the validity of our models, we provide some evidence for the existence of associations between RTW following rehabilitation including vocational aspects and both recalled social support and physical demand on the workplace previous to the rehabilitation program. Independently from the confounders, the chances of returning to work at any of the three time points increase with increasing perceived social support. Our findings do not rule out the possibility of no effect but these associations are more likely than not (see confidence intervals). Furthermore, the fact that the odds-ratios were rather consistent between time points and between both adjustment methods adds to the confidence one can have about an effect of social support. A second finding of the present study is that increased recalled physical demand results in decreasing chance of being working one year after rehabilitation. Depending on the method of adjustment, negative three-month effects of remembered physical or psychological demand might exist but the results are not conclusive. Our models are also compatible with a positive effect of job strain on RTW one year after rehabilitation, although with a high degree of imprecision in the estimations.

The association of social support at the workplace with RTW has been shown by previous research, using either Karasek's JCQ or other instruments [2, 34-36]. Another qualitative study pointed out the search for contacts with the employer and a need to create a positive emotional atmosphere at the workplace [37]. The JCQ measures perceived support from colleagues and superiors at work. In a rehabilitation program it is difficult to influence work conditions. Perceived social support at the workplace seems however to be a modifiable dimension that may be influenced, for example, by increasing contacts between employer and rehabilitation team. Such possibility should be emphasized in multi-oriented rehabilitation plans and the effect of strengthening social support at the workplace should be assessed in intervention studies.

Compared to a reference study of over 11,000 workers of the French national electric and gas company (EDF-GDF) [25], our sample had a twice higher mean physical demand score (15.3 in ours, 7.7 in the French study) but similar mean values for job control (71.2 in both), psychological demand ( 24.1 in ours vs. 22.7 in the French study) and social support ( 23.2 vs. 22.0 respectively). Thus, the workplace perception of our study population was comparatively more affected by physical demand than by the other JCQ dimensions. Several other studies report decreased chances of RTW for 
subjects who have experienced stronger physical job demands [38-40]. In a rehabilitation setting, modification in patients' perception of physical demand could be achieved with progressive physical reconditioning or a progressive RTW schedule, as it has been shown by Krause et al in a review of the literature [41]. Ergonomic intervention is another possibility of influencing both physical demand perceptions and social support at the workplace. The fact that the perceived physical demand effect is inconclusive after 2 years might be explained by the population studied, mainly blue-collar, loweducated workers. For financial reasons, some might have needed to go back to work, having no hope for any professional reclassification.

Thus, efforts to improve work conditions in general should be encouraged. Our results can be read under the light of disability management literature. Systematic reviews [42-44] found evidence that workplace-based interventions could reduce work disability duration and its costs. In a review, Shaw et al. [45] retained three aspects that appear to be most important: social problem solving, workplace mediation and ergonomics-workplace assessment. Our results fit all three aspects.

Our finding that high job strain should bear higher chances to go back to work one year after rehabilitation seems rather counterintuitive and contradicts other published results [18]. Three months and 1 year after rehabilitation, a higher proportion of working high strain subjects, compared to low strain ones, had found a job of a different kind than before the injury (3 months: $44 \%$ for high strain vs $23 \%$ for low strain; 1 year: $47 \%$ for high strain vs 35\% for low strain). The reverse happened 2 years after rehabilitation (37\% for high strain vs $62 \%$ for low strain). Persons who have changed their professional activity are likely to have benefitted from further vocational reinsertion measures, which are mainly provided early after the rehabilitation program. The above figures suggest therefore that a higher proportion of the high strain group, compared to low strain, may have benefitted from reinsertion help facilitating the finding of a new job. Two years post-rehabilitation, the effect of early reinsertion measures would be lost, allowing for the low strain group to have then a higher proportion of job changes. These explanations remain speculative because we do not have the data to check them. Both high and low strain subjects were similarly distributed between the service sector and the production and construction sector before the accident (high strain: 31\% service, 69\% production and construction; low strain: $30 \%$ service, $67 \%$ production and construction, $3 \%$ other). On the other hand some degree of selection bias may have influenced our results. The fact that a lower proportion of high strain subjects (57\%) responded to the one-year OUTCOME questionnaire compared to the low strain (70\%) may have biased our estimation towards a higher odds-ratio. Furthermore our estimation was imprecise (broad confidence interval) probably due to the small number of high strain subjects.

The present study differs from much previous research by including the four individual JCQ dimensions in addition to the job strain variable. Researchers have often stressed job strain as a comprehensive measure of work related stress. If there is consensus about the usefulness of Karasek's job strain as a measure of work related stress, there is no consensus on how job strain should be calculated. The formulation we used $[18,46,47]$, is possibly the most frequently used. Different formulations have been applied in the published research. Sometimes, job strain has been constructed with the additional inclusion of the social support variable[19]. Other formulations include, for instance, the quotient of psychological demand by job control $[18,39]$, the subtraction of psychological demand from job control [48] or the multiplicative interaction of the two variables [48]. Moreover, within each formulation, job strain can be categorized in different ways. It has been analysed as a binary variable as we did [18, 46, 47, 49]; as a four-category variable with one category as reference[18, 19]; as decile-categories of a continuous variable [39]; as a continuous variable [48]. The results of a study can depend on the way job strain is calculated. For example, the degree of evidence for an association between job strain and carotid intima-media thickness differed among five job strain formulations applied to the same data set [48]. Therefore, notwithstanding the usefulness of job strain as a measure of work related stress, its calculation may produce questionable results. Here we argue that considering the JCQ dimensions individually can still produce results that are useful to guide workplace intervention and that may be easier to interpret than the job strain variable.

\section{Study limitations}

Our subjects were mainly blue collar men sent to our rehabilitation hospital after orthopedic trauma and were subject to comparatively high levels of physical demand at their pre-rehabilitation workplace. 
Therefore, our results should not be generalized to non-trauma patients and might not apply to populations that experience only low levels of physical demand.

The potential confounders we controlled for in our statistical models were chosen based on prior literature knowledge. Since we cannot be sure that all relevant potential confounders were accounted for, there may be some degree of uncontrolled confounding bias in our results. In particular, we did not ask our patients whether they foresaw going back to their previous employment after the rehabilitation as this variable has been shown to be associated with RTW in some studies [50,51], and could be associated with the JCQ dimensions. However, this variable was partly controlled for by the question about the possession of a work contract before starting the rehabilitation. Furthermore, subjects were not asked whether they actually had a job before entering the rehabilitation hospital.

Some degree of nonresponse bias cannot be excluded either. Assuming that the probability of responding to the OUTCOME questionnaires is not associated with the work variable, (i.e. the responses are missing at random, MAR), adjusting the analyses for the variables associated with the probability of responding would control for nonresponse bias[52]. We were able to adjust for two variables, native language and educational level, that we previously found to be associated to the probability of responding to the OUTCOME questionnaires [33]. However, we could not adjust for a third relevant variable, INTERMED complexity [33] , because data were not available for all subjects. Furthermore, we cannot be sure that no other variable associated with response has been neglected. Thus, assuming our data are MAR our analysis probably reduced nonresponse bias without eliminating it completely.

\section{Conclusion}

Our results suggest that recalled social support and physical demand at work influence RTW after rehabilitation. Work condition improvements in general could modify those perceptions in the long term. Besides the relevant rehabilitation measures, efforts should be made to try to modify peceptions of work environment, for example with cognitive behavioural interventions. In a rehabilitation setting, efforts should be made to increase contacts with employers to try to find individual solutions to help workers progressively go back to their previous work, or help them find a work adapted to their limitations. Such interventions could help diminish the social costs of sick leave and reduced productivity.

Acknowledgements We thank Viviane Dufour, Antoinette Crettenand, and Aaron Russell, PhD, for all the work related to the preparation of the OUTCOME questionnaires, the data collection and data entry. Peter Erhart, PhD, Hanspeter Gmünder, MD, and Nikola Seichert, PhD, collaborated in the design of the OUTCOME project. Elisabeth Conne-Perréard, MD, drew our attention to the JCQ.

The Clinique romande de réadaptation belongs to SUVA, the Swiss national accident insurance. This work was supported by SUVA (grant no. 100204). 


\section{References}

1. Gobelet C, Franchignoni F. Vocational rehabilitation. In: Gobelet C, Franchignoni F eds. Vocational rehabilitation. Paris: Springer-Verlag; 2006, p. 3-16.

2. Selander J, Marnetoft SU, Bergroth A, Ekholm J. Return to work following vocational rehabilitation for neck, back and shoulder problems: risk factors reviewed. Disabil Rehabil 2002; 24:704-12.

3. Iles RA, Davidson M, Taylor NF. Psychosocial predictors of failure to return to work in non-chronic non-specific low back pain: a systematic review. Occup Environ Med. 2008; 65:507-17.

4. Krause N, Frank JW, Dasinger LK, Sullivan TJ, Sinclair SJ. Determinants of duration of disability and return-to-work after work-related injury and illness: challenges for future research. Am J Ind Med. 2001; 40:464-84.

5. MacEachen E, Clarke J, Franche RL, Irvin E. Systematic review of the qualitative literature on return to work after injury. Scand J Work Environ Health. 2006; 32:257-69.

6. Oyeflaten I, Hysing M, Eriksen HR. Prognostic factors associated with return to work following multidisciplinary vocational rehabilitation. J Rehabil Med. 2008; 40:548-54.

7. Waddell G, Newton M, Henderson I, Somerville D, Main CJ. A Fear-Avoidance Beliefs Questionnaire (FABQ) and the role of fear-avoidance beliefs in chronic low back pain and disability. Pain. 1993; 52:157-68.

8. Selye H. A syndrome produced by diverse nocuous agents. Nature. 1936; 138: 32.

9. Karasek R. J ob demands, job decision latitude, and mental strain: implication for job redesign. Adm Sci Q. 1979; 24:285-308.

10. Karasek R, Theorell T. Healthy work: stress, productivity, and the reconstruction of working life. New York: Basic Books, 1990.

11. Peter R, Siegrist J. Psychosocial work environment and the risk of coronary heart disease. Int Arch Occup Environ Health. 2000; 73 Suppl:S41-5.

12. Schnall PL, Landsbergis PA, Baker D. Job strain and cardiovascular disease. Annu Rev Public Health. 1994; 15: 381-411.

13. Toivanen $\mathrm{S}$, Hemstrom $\mathrm{O}$. Is the impact of job control on stroke independent from socioeconomic status?: a large-scale study of the Swedish working population. Stroke. 2008; 39: 1321-3.

14. Tsutsumi A, Kayaba K, Kario K, Ishikawa S. Prospective study on occupational stress and risk of stroke. Arch Intern Med. 2009; 169:56-61.

15. Ijzelenberg W, Molenaar D, Burdorf A. Different risk factors for musculoskeletal complaints and musculoskeletal sickness absence. Scand J Work Environ Health. 2004; 30: 56-63.

16. Krause N, Ragland DR, Fisher JM, Syme SL. Psychosocial job factors, physical workload, and incidence of work-related spinal injury: a 5-year prospective study of urban transit operators. Spine. 1998; 23:2507-16.

17. Torp S, Riise T, Moen BE. The impact of psychosocial work factors on musculoskeletal pain: a prospective study. J Occup Environ Med. 2001; 43:120-6.

18. Gimeno D, Amick BC, 3rd, Habeck RV, Ossmann J, Katz JN. The role of job strain on return to work after carpal tunnel surgery. Occup Environ Med. 2005; 62: 77885.

19. Moreau M, Valente F, Mak R, Pelfrene E, de Smet P, De Backer G et al. Occupational stress and incidence of sick leave in the Belgian workforce: the Belstress study. J Epidemiol Community Health. 2004; 58:507-16.

20. Josephson M, Heijbel B, Voss M, Alfredsson L, Vingard E. Influence of selfreported work conditions and health on full, partial and no return to work after long-term sickness absence. Scand J Work Environ Health. 2008; 34:430-7. 
21. Heymans MW, de Vet HC, Knol DL, Bongers PM, Koes BW, van Mechelen W. Workers' beliefs and expectations affect return to work over 12 months. J Occup Rehabil. 2006; 16:685-95.

22. Schultz IZ, Crook J, Meloche GR, Berkowitz J, Milner R, Zuberbier OA et al. Psychosocial factors predictive of occupational low back disability: towards development of a return-to-work model. Pain. 2004; 107:77-85.

23. Fritz JM, George SZ. I dentifying psychosocial variables in patients with acute work-related low back pain: the importance of fear-avoidance beliefs. Phys Ther. 2002; 82:973-83.

24. Feuerstein M, Callan-Harris S, Hickey P, Dyer D, Armbruster W, Carosella AM. Multidisciplinary rehabilitation of chronic work-related upper extremity disorders. Long-term effects. J Occup Med. 1993; 35:396-403.

25. Niedhammer I. Psychometric properties of the French version of the Karasek J ob Content Questionnaire: a study of the scales of decision latitude, psychological demands, social support, and physical demands in the GAZEL cohort. Int Arch Occup Environ Health. 2002; 75:129-44.

26. AAAM. Abbreviated Injury Scale (AIS) 1990 - update 1998. Barrington, IL: Association for the advancement of automotive medicine, 2001.

27. Peduzzi P, Concato J, Kemper E, Holford TR, Feinstein AR. A simulation study of the number of events per variable in logistic regression analysis. J Clin Epidemiol. 1996; 49: 1373-9.

28. Hosmer DW, Lemeshow S. Applied logistic regression. New York: J ohn Wiley and sons, 2000.

29. Sturmer T, Schneeweiss S, Brookhart MA, Rothman KJ, Avorn J, Glynn RJ . Analytic strategies to adjust confounding using exposure propensity scores and disease risk scores: nonsteroidal antiinflammatory drugs and short-term mortality in the elderly. Am J Epidemiol. 2005; 161:891-8.

30. Imai K, van Dyk DA. Causal inference with generalized treatment regimes: generalizing the propensity score. J Am Stat Assoc. 2004; 99: 854-66.

31. Royston $P$, Ambler G, Sauerbrei W. The use of fractional polynomials to model continuous risk variables in epidemiology. Int J Epidemiol. 1999; 28:964-74.

32. StataCorp. Stata statistical software: release 9. College Station, Texas: StataCorp LP, 2005.

33. Burrus C, Ballabeni P, Deriaz O, Gobelet C, Luthi F. Predictors of nonresponse in a questionnaire-based outcome study of vocational rehabilitation patients. Arch Phys Med Rehabil. 2009; 90: 1499-505.

34. Soucy I, Truchon M, Cote D. Work-related factors contributing to chronic disability in low back pain. Work. 2006; 26:313-26.

35. Bonde JP, Mikkelsen S, Andersen JH, Fallentin N, Baelum J, Svendsen SW et al. Prognosis of shoulder tendonitis in repetitive work: a follow up study in a cohort of Danish industrial and service workers. Occup Environ Med. 2003; 60: E8.

36. Mielenz TJ, Garrett J M, Carey TS. Association of psychosocial work characteristics with low back pain outcomes. Spine. 2008; 33:1270-5.

37. Nordqvist C, Holmqvist C, Alexanderson K. Views of laypersons on the role employers play in return to work when sick-listed. J Occup Rehabil. 2003; 13:1120.

38. Krause N, Dasinger LK, Deegan LJ, Rudolph L, Brand RJ. Psychosocial job factors and return-to-work after compensated low back injury: a disability phase-specific analysis. Am J Ind Med. 2001; 40:374-92.

39. Laaksonen M, Martikainen $\mathrm{P}$, Rahkonen O, Lahelma E. Explanations for gender differences in sickness absence: evidence from middle-aged municipal employees from Finland. Occup Environ Med. 2008; 65:325-30. 
40. Mackenzie EJ, Morris JA, J r., Jurkovich GJ, Yasui Y, Cushing BM, Burgess AR et al. Return to work following injury: the role of economic, social, and job-related factors. Am J Public Health. 1998; 88: 1630-7.

41. Krause N, Dasinger LK, Neuhauser F. Modified work and return to work: A review of the literature. J Occup Rehabil. 1998; 8:113-39.

42. Franche RL, Cullen K, Clarke J, Irvin E, Sinclair S, Frank J. Workplace-based return-to-work interventions: a systematic review of the quantitative literature. J Occup Rehabil. 2005; 15:607-31.

43. Tompa E, de Oliveira C, Dolinschi R, Irvin E. A systematic review of disability management interventions with economic evaluations. J Occup Rehabil. 2008; 18: 16-26.

44. Williams RM, Westmorland M. Perspectives on workplace disability management: a review of the literature. Work. 2002; 19:87-93.

45. Shaw W, Hong QN, Pransky G, Loisel P. A literature review describing the role of return-to-work coordinators in trial programs and interventions designed to prevent workplace disability. J Occup Rehabil. 2008; 18:2-15.

46. Krause N, Rugulies R, Maslach C. Effort-reward imbalance at work and self-rated health of Las Vegas hotel room cleaners. Am J Ind Med. 2010; 53:372-86.

47. Landsbergis PA, Schnall PL, Pickering TG, Schwartz JE. Validity and reliability of a work history questionnaire derived from the J ob Content Questionnaire. J Occup Environ Med. 2002; 44: 1037-47.

48. Hintsa T, Kivimaki M, Elovainio M, Vahtera J, Hintsanen M, Viikari JS et al. Is the association between job strain and carotid intima-media thickness attributable to pre-employment environmental and dispositional factors? The Cardiovascular Risk in Young Finns Study. Occup Environ Med. 2008; 65:676-82.

49. Hallqvist J, Diderichsen F, Theorell T, Reuterwall C, Ahlbom A. Is the effect of job strain on myocardial infarction risk due to interaction between high psychological demands and low decision latitude? Results from Stockholm Heart Epidemiology Program (SHEEP). Soc Sci Med. 1998; 46: 1405-15.

50. Fadyl J, McPherson K. Return to work after injury: a review of evidence regarding expectations and injury perceptions, and their influence on outcome. J Occup Rehabil. 2008; 18:362-74.

51. Heijbel B, Josephson M, Jensen I, Stark S, Vingard E. Return to work expectation predicts work in chronic musculoskeletal and behavioral health disorders: prospective study with clinical implications. J Occup Rehabil. 2006; 16:173-84.

52. Sterne JA, White IR, Carlin JB, Spratt M, Royston P, Kenward MG et al. Multiple imputation for missing data in epidemiological and clinical research: potential and pitfalls. BMJ . 2009; 338: b2393. 
Table 1 Values of the predictors and confounders at the end of rehabilitation.

\begin{tabular}{|c|c|c|c|}
\hline Variable & Category & $\mathbf{n}^{\dagger}$ & $\begin{array}{l}\text { Mean } \pm \text { sd } \\
\text { or freq }(\%)\end{array}$ \\
\hline \multicolumn{4}{|l|}{ Predictors: } \\
\hline Job control* & . & 277 & $71.2 \pm 13.9$ \\
\hline Psychological demand* & . & 271 & $24.1 \pm 4.5$ \\
\hline Social support* & . & 266 & $23.2 \pm 4.3$ \\
\hline Physical demand* & . & 278 & $15.3 \pm 4.1$ \\
\hline Job strain & $\begin{array}{l}\text { High } \\
\text { Low }\end{array}$ & 269 & $\begin{array}{c}60(22.3) \\
209(77.7)\end{array}$ \\
\hline \multicolumn{4}{|l|}{ Confounders: } \\
\hline Age (years) & . & 291 & $42.0 \pm 10.8$ \\
\hline Gender & $\begin{array}{l}\text { Women } \\
\text { Men }\end{array}$ & 291 & $\begin{array}{c}68(23.4) \\
223(76.6)\end{array}$ \\
\hline Native language & $\begin{array}{l}\text { Other } \\
\text { French }\end{array}$ & 291 & $\begin{array}{l}91(31.3) \\
200(68.7)\end{array}$ \\
\hline Education & $\begin{array}{l}<=9 \text { years } \\
>9 \text { years }\end{array}$ & 291 & $\begin{array}{l}182(62.5) \\
109(37.5)\end{array}$ \\
\hline Work contract at admission & $\begin{array}{l}\text { No } \\
\text { Yes }\end{array}$ & 291 & $\begin{array}{l}119(40.9) \\
172(59.1)\end{array}$ \\
\hline Pain (visual analogue scale) & . & 291 & $47.1 \pm 26.8$ \\
\hline Severity of injury (AIS) & . & 291 & $2.07 \pm 0.90$ \\
\hline
\end{tabular}




\begin{tabular}{|l|l|l|c|}
\hline Patients'expectations on own health outcome & No improvement & 291 & $82(28.2)$ \\
Improvement & $209(71.8)$ \\
\hline
\end{tabular}

* Lowest and highest possible scores: job control, 24-96; psychological demand, 9-36; social support, 8-32; physical demand, 5-20.

${ }^{\dagger}$ All predictors could not be assessed for every subject due to missing values. 
Table 2 Summary statistics for return to work status at each time point.

\begin{tabular}{|c|c|c|c|c|c|c|c|c|c|c|c|c|}
\hline \multirow[b]{2}{*}{ Variable } & \multicolumn{4}{|c|}{3 months } & \multicolumn{4}{|c|}{1 year } & \multicolumn{4}{|c|}{2 years } \\
\hline & $\mathbf{n}^{\dagger}$ & $\begin{array}{l}\text { Mean } \pm \text { sd } \\
\text { or freq } \\
\text { (column } \\
\% \text { ) }\end{array}$ & $\mathbf{n}^{\dagger}$ & $\begin{array}{l}\text { Mean } \pm \text { sd } \\
\text { or freq } \\
\text { (column } \\
\% \text { ) }\end{array}$ & $\mathbf{n}^{\dagger}$ & $\begin{array}{l}\text { Mean } \pm \text { sd } \\
\text { or freq } \\
\text { (column } \\
\% \text { ) }\end{array}$ & $\mathbf{n}^{\dagger}$ & $\begin{array}{l}\text { Mean } \pm \text { sd } \\
\text { or freq } \\
\text { (column } \\
\%)\end{array}$ & $\mathbf{n}^{\dagger}$ & $\begin{array}{l}\text { Mean } \pm \text { sd } \\
\text { or freq } \\
\text { (column } \\
\%)\end{array}$ & $\mathbf{n}^{\dagger}$ & $\begin{array}{l}\text { Mean } \pm \text { sd } \\
\text { or freq } \\
\text { (column } \\
\% \text { ) }\end{array}$ \\
\hline \multicolumn{13}{|l|}{ Predictors: } \\
\hline Job control* & 83 & $71.1 \pm 12.6$ & 141 & $71.4 \pm 14.1$ & 83 & $72.9 \pm 12.0$ & 100 & $71.1 \pm 14.7$ & 86 & $72.4 \pm 13.0$ & 64 & $70.4 \pm 14.2$ \\
\hline Psychological demand* & 82 & $22.9 \pm 4.2$ & 140 & $24.7 \pm 4.7$ & 82 & $23.3 \pm 4.3$ & 101 & $24.5 \pm 4.5$ & 85 & $23.4 \pm 4.4$ & 65 & $24.3 \pm 4.4$ \\
\hline $\begin{array}{l}\text { High strain job } \\
\text { Low strain job }\end{array}$ & 81 & $\begin{array}{l}16(19.8) \\
65(80.2)\end{array}$ & 139 & $\begin{array}{l}32(23.0) \\
107(77.0)\end{array}$ & 81 & $\begin{array}{l}19(23.5) \\
62(76.5)\end{array}$ & 100 & $\begin{array}{l}15(15.0) \\
85(85.0)\end{array}$ & 85 & $\begin{array}{l}16(18.8) \\
69(81.2)\end{array}$ & 63 & $\begin{array}{l}14(22.2) \\
49(77.8)\end{array}$ \\
\hline
\end{tabular}




\begin{tabular}{|c|c|c|c|c|c|c|c|c|c|c|c|c|}
\hline Age (years) & 87 & $44.3 \pm 11.1$ & 148 & $42.2 \pm 10.3$ & 87 & $43.1 \pm 10.7$ & 105 & $43.8 \pm 9.9$ & 89 & $43.9 \pm 9.9$ & 70 & $45.4(9.9)$ \\
\hline $\begin{array}{l}\text { French language } \\
\text { Other language }\end{array}$ & 87 & $\begin{array}{l}66(75.9) \\
21(24.1)\end{array}$ & 148 & $\begin{array}{l}91(61.5) \\
57(38.5)\end{array}$ & 87 & $\begin{array}{l}68(78.2) \\
19(21.8)\end{array}$ & 105 & $\begin{array}{l}66(62.9) \\
39(37.1)\end{array}$ & 89 & $\begin{array}{l}66(74.2) \\
23(25.8)\end{array}$ & 70 & $\begin{array}{l}46(65.7) \\
24(34.3)\end{array}$ \\
\hline $\begin{array}{l}\text { Job contract } \\
\text { No contract }\end{array}$ & 87 & $\begin{array}{l}67(77.0) \\
20(23.0)\end{array}$ & 148 & $\begin{array}{l}75(50.7) \\
73(49.3)\end{array}$ & 87 & $\begin{array}{l}65(74.7) \\
22(25.3)\end{array}$ & 105 & $\begin{array}{l}57(54.3) \\
48(45.7)\end{array}$ & 89 & $\begin{array}{l}62(69.7) \\
27(30.3)\end{array}$ & 70 & $\begin{array}{l}36(51.4) \\
34(48.6)\end{array}$ \\
\hline Severity of injury (AIS) & 87 & $2.05 \pm 0.82$ & 148 & $2.13 \pm 0.90$ & 87 & $2.12 \pm 0.80$ & 105 & $2.13 \pm 0.94$ & 89 & $2.23 \pm 0.84$ & 70 & $2.09 \pm 0.87$ \\
\hline $\begin{array}{l}\text { Expecting improvement } \\
\text { Expecting no improv. }\end{array}$ & 87 & $\begin{array}{l}69(79.3) \\
18(20.7)\end{array}$ & 148 & $\begin{array}{l}97(65.5) \\
5134.5)\end{array}$ & 87 & $\begin{array}{l}72(82.8) \\
15(17.2)\end{array}$ & 105 & $\begin{array}{l}66(62.9) \\
39(37.1)\end{array}$ & 89 & $\begin{array}{l}71(79.8) \\
18(20.2)\end{array}$ & 70 & $\begin{array}{l}44(62.9) \\
26(37.1)\end{array}$ \\
\hline
\end{tabular}

* Lowest and highest possible scores: job control, 24-96; psychological demand, 9-36; social support, 8-32; physical demand, 5-20.

${ }^{\dagger}$ All predictors could not be assessed for every subject due to missing values. 


\section{Figure legends}

Figure 1. Odds-ratios and 95\% confidence intervals for the $4 \mathrm{JCQ}$ dimensions. The ORs are for increments of 1 standard deviation in the independent variable. The confounder-adjusted models are adjusted for a predictor's propensity score, this being different at each time point. The fully adjusted models are adjusted by the predictor's propensity score plus the three remaining JCQ dimensions.

Figure 2. Odds-ratios and 95\% confidence intervals for job strain. The confounderadjusted models are adjusted for job strain's propensity score, which is different at each time point. The fully adjusted models are adjusted for strain's propensity score plus social support and physical demand. 
Figure 1

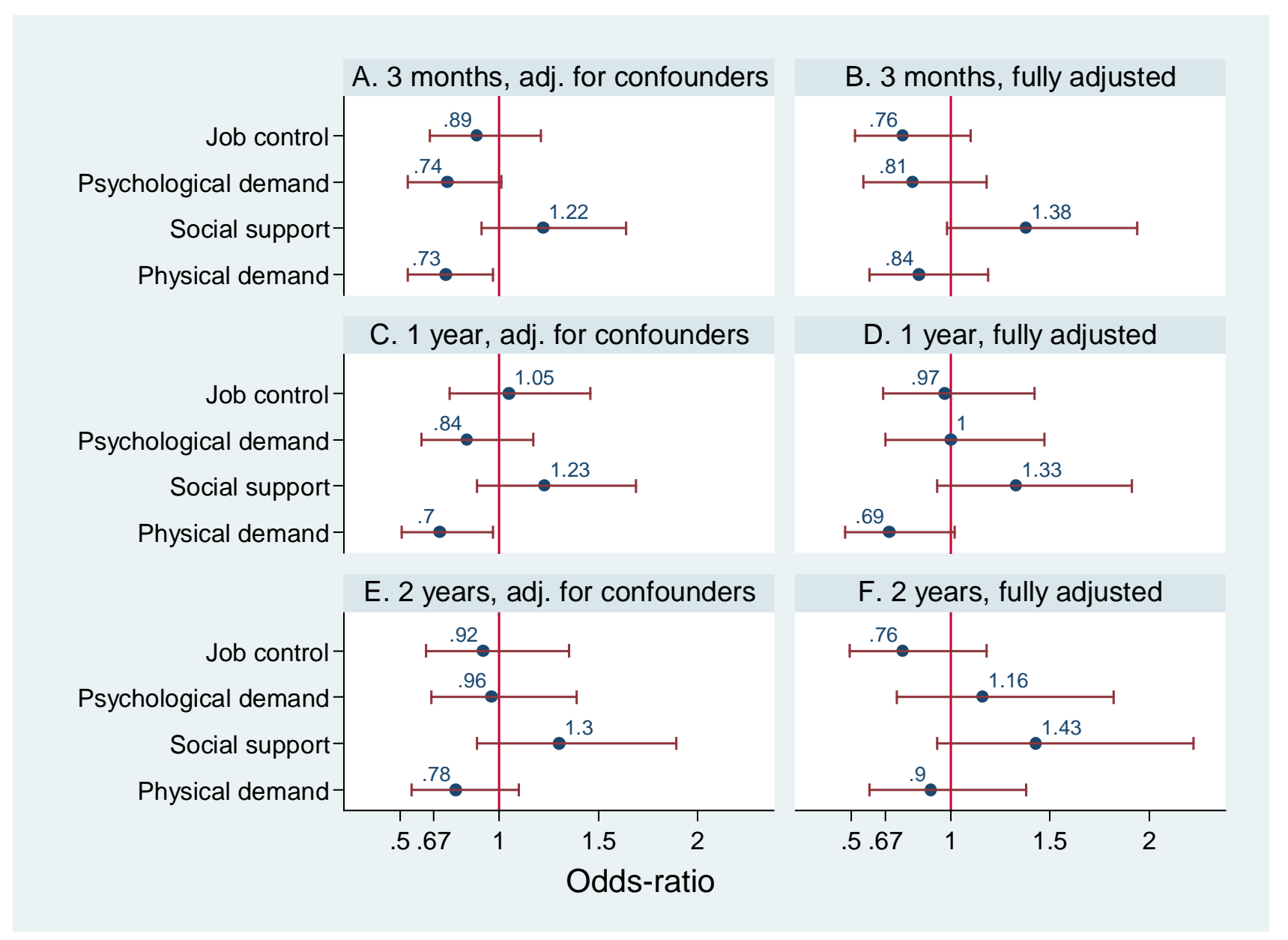




\section{Figure 2}

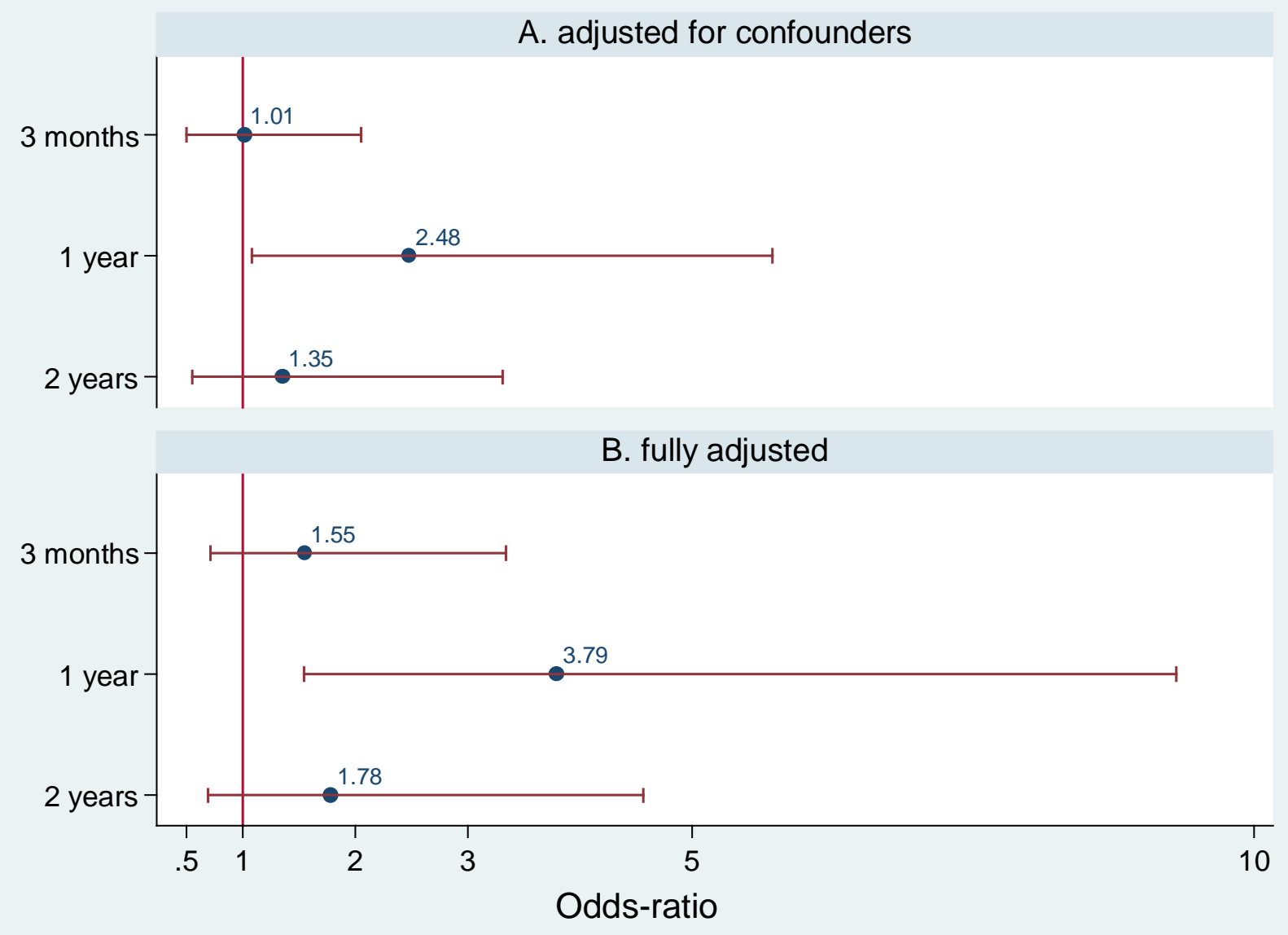

